Issn: 1808 - 799X

ano 11, no $16-2013$

Memória e Documentos

\title{
ANGICOS/1963: UM MARCO HISTÓRICO DA EDUCAÇÃO NO BRASIL
}

Francisco José da Silveira Lobo Neto

\section{Introdução:}

Em 1963, realizava-se em Angicos (RN), uma experiência cujas repercussões - políticas e pedagógicas - marcaram fortemente a história da educação brasileira.

Os fatos históricos, contudo, não podem entender-se plenamente sem o contexto dos processos históricos que, antes e depois, dão-lhes a importância de serem sínteses e imagens marcantes.

Angicos, no Rio Grande do Norte, como experiência pedagógica, dá visibilidade a um trabalho que se vai construindo em um grupo dinâmico de pessoas, inegavelmente sob a liderança de Paulo Freire.

O próprio Paulo Freire, no "Cartas a Cristina", resgatando sua atuação nos Clubes do SESI (Décima Primeira Carta) nos dá seu testemunho sobre a construção coletiva de sua proposta para a "alfabetização" de adultos.

Sem a intenção de fazer História, ele historiciza sua trajetória, marcada pelo respeito aos sujeitos do processo politico-pedagógico. Assim é que, na 


\section{Trabalhonecessário}

Issn: 1808 - 799X

ano $11, \mathrm{n}-16-2013$

Décima Segunda Carta, revela seus passos desde o Movimento de Cultura Popular do Prefeito Miguel Arraes até o Serviço de Extensão Cultural da Universidade do Recife. E reflete o seu protagonismo - e o deste Serviço - na experiência de Angicos, provocada por Calazans Fernandes, Secretário de Educação do Estado do Rio Grande do Norte, no Governo Aluizio Alves.

Embora sendo impreciso na data - "não me lembro de que mês de 1963" (na verdade tratava-se de setembro de 1962) -, Paulo Freire relata minuciosamente a proposta de Calazans e as condições que impôs para cooperar com o governo de Rio Grande do Norte: convênio do RN com o SEC/UR, garantindo autonomia e condições de trabalho; liberdade de colaborar com a Prefeitura de Natal, cujo Secretário de Educação era Moacir de Góes; coordenação da Universidade do Recife, em estreita relação com o Secretário de Educação; e "o governador do Estado deveria precaver-se de, durante os trabalhos, fazer visitas aos centros ou aos círculos de cultura para evitar exploração política".

O convênio foi assinado em 3 de dezembro de 1962, com a interveniência da SUDENE e da USAID/Aliança para o Progresso. Neste mesmo mês, o estudante de Direito Marcos Guerra, presidente da União Estadual de Estudantes, foi encarregado de formar a equipe que coordenaria os trabalhos nos Círculos de Cultura a serem instalados em Angicos. Na relação nominal dos coordenadores, preservada por Carlos Augusto Lyra Martins em seu livro "As quarenta horas de Angicos: uma experiência pioneira de educação" (Lyra, 1996: 118), contam-se 2 secundaristas e entre os universitários, 7 estudantes de Filosofia, 1 de Farmácia, 4 de Direito, 1 de Odontologia, 2 de Serviço Social, 1 de Pedagogia e 3 de Medicina.

Embora a aula inaugural sobre Cultura - com a presença do Governador Aluízio Alves - tenha ocorrido no dia 18 de janeiro de 1963, o início da 


\section{Trabalhonecessário}

Issn: 1808 - 799X

ano $11, \mathrm{n}-16-2013$

Alfabetização só aconteceu no dia 28 de janeiro, com a palavra geradora "belota" (cfr. Lyra, 1996: 34-39) tendo a participação de 254 alfabetizandos. Sucederam-se os encontros, mais frequentes (quase cotidianos) no mês de fevereiro e primeira metade de março.

O sábado, 16 de março foi o "último dia de aula" registrado pelo Carlos Lyra (1996: 108-109): “Os participantes, apreensivos, indagam diariamente, sobre o final do curso. Decidimos encerrar sem avisá-los antecipadamente, pois eles afirmavam que não iriam ao último debate. Foi a 'aula da saudadezinha'. Fizemos um breve histórico do curso (...). Em nome dos alunos falaram o Sr. Antônio Ferreira e o Sr. Geraldo que, emocionado, disse: - Foi muito pouco tempo, mas hoje já sei ler. Não uso mais o dedo, agora escrevo o meu nome. Como é que eu devo provar? É lendo"(idem: 109).

Ficou marcado, para o dia 22 de março, o "encerramento oficial". O presidente João Goulart estaria presente à quadragésima hora. Adiada a visita do presidente ao Rio Grande do Norte, a última aula ocorreu na terça feira, dia 2 de abril, "numa solenidade milionária de autoridades" (ibidem). Sentados à mesa, ao lado do Presidente da República, entre outros, os Governadores de Pernambuco (Miguel Arraes), Sergipe (Seixas Dória), Ceará (Virgílio Távora) e Rio Grande do Norte (Aluízio Alves; o Ministro da Educação (Theotônio Monteiro de Barros), o Superintendente da SUDENE (Celso Furtado), o Comandante do IV Exército (Humberto Castelo Branco) e Sílvio Pedroza, exGovernador do Estado (1951-1956). Paulo Freire e Calazans Fernandes, com os coordenadores dos Círculos de Cultura e os próprios participantes do processo educativo, sujeitos conscientes de que se vivia um momento/marco histórico.

E ninguém melhor, para dizer isso, do que Antônio Ferreira, falando em nome dos participantes, no registro de Lyra (1996: 115-116): "Em outra hora, 


\section{Trabalhonecessário}

Issn: 1808 - 799X

ano $11, \mathrm{n}-16-2013$

nós era massa. Hoje, já não somos massa, estamos sendo povo. Nós todos, alunos, uns trezentos e tantos ou quatrocentos, já sabemos escrever qualqué coisa, e ler outras coisas. Com a continuação, amanhã ou adepois, sabemos escrever as cartilhas do presidente da República, sabemos fazer qualqué coisa em favor do Brasil, em favor do Estado".

Angicos foi uma experiência pedagógica plena e, por isso mesmo, foi política, como radicalmente políticas - resvalando para politiqueiras - as que se proclamam apolíticas. Nada mais eloquente do que a menção do General Castelo Branco ao Secretário Calazans Fernandes - ouvida e registrada por Carlos Lyra (idem: 117) - sobre estar "engordando cascavéis neste sertão". Isto, depois de tecer, "de próprio punho", no caderno de anotações do coordenador Talvani Guedes, "elogiosas referências ao nosso trabalho".

A reportagem de $\mathrm{O}$ Globo, dois dias após o encerramento, comunica a expressa intenção presidencial de expandir nacionalmente a experiência de Angicos. E, de fato, já no segundo semestre de 1963, como projeto piloto do Programa Nacional de Alfabetização, são implantados processos de alfabetização, tendo por base a realização de Angicos, em Quintas (Natal), Mossoró, Caicó, Macau, Ubatuba, Osasco, Rio de Janeiro, Brasília, Aracaju, Porto Alegre e outras.

A formalização do Programa Nacional de Alfabetização pelo Decreto no 53.465, de 21 de Janeiro de 1964, em seu primeiro Artigo define:

"Art. 1ํ Fica instituído o Programa Nacional de Alfabetização, mediante o uso do Sistema Paulo Freire, através do Ministério da Educação e Cultura".

Antes de completar o seu terceiro mês, logo após o golpe de Estado de 1 de abril, o Decreto nํ 53.886, de 14 de abril de 1964, (véspera da posse do Marechal Humberto de Alencar Castelo Branco na presidência da República, por uma maioria de congressistas acovardados diante do poder militar)

TrabalhoNecessário - www.uff.br/trabalhonecessario; Ano 11, № 16/2013. 


\title{
Trabalhonecessário
}

\author{
Issn: 1808 - 799X \\ ano 11, no $16-2013$
}

extingue o Programa, determinando o recolhimento de "todo o acervo empregado na execução do Programa Nacional de Alfabetização". Determinação coerente com a obcessiva intenção de tutelar autoritariamente as idéias em nome da democracia, expressa em um dos consideranda:

\footnotetext{
"CONSIDERANDO ainda que o material a ser empregado na Alfabetização da População Nacional deverá veicular idéias nìtidamente democráticas e preservar as instituições e tradições de nosso povo;".
}

Paulo Freire é preso em junho e se vê - ameaçado - na necessidade de exilar-se. E foi bem recebido no mundo. Muito - e de muitas formas - se tentou explicar seu sucesso e o sucesso de seu método. Creio que nada melhor para explicá-lo do que a síntese apresentada num trecho de sua explanação no dia 2 de abril de 1963 em Angicos: "Quebramos uma série de tabus metodológicos. Superamos a escola pelo que nós chamamos Círculo de Cultura; o aluno, pelo participante de debates; a aula pelo diálogo; o programa acadêmico por situações sociológicas desafiadoras, que nós pomos diante dos grupos com quem debatemos e de quem arrancamos uma sabedoria que existe e que é, esta sabedoria, opinativa e existencial do povo" (Lyra, 1996: 116).

Estamos trazendo para os leitores, alguns Documentos disponíveis, sobre o estado da reflexão sobre a questão no final da década de 1950 (Documento 1); a reportagem do correspondente de O Globo, imediatamente após o encerramento da experiência de Angicos (Documento 2); o texto de Antonio Callado, publicado no JB, uma semana antes da criação do Programa Nacional de Alfabetização (Documento 3); Os Decretos de criação e extinção do Programa (Documentos 4 e 5) e, finalmente, as entrevistas/depoimentos de Osmar Fávero e Marcos Guerra gravadas e disponibilizadas na Internet (Documentos 6 e 7).

TrabalhoNecessário - www.uff.br/trabalhonecessario; Ano 11, № 16/2013. 


\section{Trabalhonecessário}

Issn: $1808-799 X$

ano $11, \mathrm{n}=16-2013$

Dada a natureza desta coluna, as referências bibliográficas se referem apenas às obras de atores participantes da experiência de Angicos, sem mencionar os trabalhos que sobre ela se produziram.

\section{Documento 1:}

Relatório Final do Seminário Regional de Educação de Adultos (Pernambuco 1958) apresentado ao II Congresso de Alfabetização de Adultos.

$2^{\mathrm{a}}$ Comissão:

Tema: O PROBLEMA DO ANALFABETISMO NO ESTADO DE PERNAMBUCO

1 - A situação em face dos dados estatísticos oficiais, apresentados pelo Departamento regional de Estatística, Inspetoria Regional de Estatística Municipal, setor de Pernambuco, Conselho Nacional de Estatística:

a) em 1958, a matrícula inicial nas escolas primárias atingiu apenas a $33 \%$ da população em idade escolar;

b) em 1957, dos 4.010.883 habitantes do Estado, sabiam ler e escrever 1.696.184, o que nos dá uma percentagem de $42,28 \%$ de letrados;

c) em 1950 a quota de alfabetização, baseada no Senso Demográfico, é de $31,75 \%$, embora marque pequeno progresso em comparação à de 1940, que é de $28,33 \%$;

d) a quota de alfabetização masculina é mais elevada do que a feminina, tanto em 1940 como em 1950; porém a diferença relativa entre as quotas de 


\section{Trabalhonecessário}

Issn: 1808 - 799X

ano $11, n=16-2013$

alfabetização dos dois sexos é menor em 1950 do que em 1940, tendo sido o progresso da alfabetização feminina maior do que o da masculina entre 1940 a 1950;

e) em relação às diferentes regiões do Estado, o resultado é o seguinte:

A quota de alfabetização mais elevada é a da zona do litoral e Mata $(33,76 \%$ em 1940 e 36,41\% em 1950); A zona do sertão do São Francisco foi a que apresentou o maior progresso (de26,34\% em 1940 para 31,90\% em 1950); A zona do Sertão Baixo e do Sertão do Araripe apresentam quotas de alfabetização ainda mais baixos (17,84\% em 1940 e 20,06\% em 1950, na Zona do Sertão Baixo, e 19,18\% em 1950, na do Sertão do Araripe); A quota mais baixa de alfabetização (16,50\% em 1940 e 18,14\% em 1950) corresponde à zona do Agreste;

f) examinando-se as quotas de alfabetização, por Municípios, encontram-se diferenças muito fortes: variam essas quotas entre os mínimos de 8,04\% em 1940 (João Alfredo) e 9,41\% em 1950 (Bom Jardim) e os máximos de 63,57\% em 1940 e 60,04 em 1950 (Recife). Em 61 municípios a quota de alfabetização é maior em 1950 do que 1940 e em 24, menor. Verificaram-se superiores a $10 \%$ da quota de alfabetização nos Municípios de Bezerros e da Jatinã. As maiores diminuições da quota de alfabetização foram verificadas nos Municípios de Gameleira, Manissobal (atual São José do Belmonte) e Recife;

g) em comparação com as outras unidades da Federação, Pernambuco ocupa o 14ํl lugar, levando-se em conta a alfabetização na população de dez (10) anos ou mais.

2 - A situação em face dos dados oficiais fornecidos pelo Instituto de Pesquisas Pedagógicas de Pernambuco:

TrabalhoNecessário - www.uff.br/trabalhonecessario; Ano 11, № 16/2013. 


\section{Trabalhonecessário}

Issn: 1808 - 799X

ano $11, \mathrm{n}-16-2013$

a) é insuficiente a rede escolar do Estado: em levantamento procedido em 1955 era de 5051 o "déficit" de escolas, ficando fora das mesmas $67 \%$ das crianças;

b) a evasão dos alunos é problema que continua a desafiar todo o esforço dos responsáveis pela educação. A percentagem mais alta obtida, nos últimos anos, de alunos que concluem a $5^{\text {a }}$ série, sobre o total da matrícula, foi de $10 \%$, registrada em 1957; é aproximadamente de $90 \%$ a evasão até a conclusão do curso;

c) em relação ao rendimento escolar, o resultado apresentado pela $1^{\text {a }}$ série, tem feito, invariavelmente, baixar de muito a percentagem de todas as escolas. A percentagem mais alta obtida nestas séries foi de $69 \%$ em 1957 , isto mesmo devido a uma maior condescendência recomendada na organização e aplicação das provas. No mesmo ano, foi de $82 \%, 82 \%, 81 \%$ e $83 \%$ a percentagem nas $2^{\underline{a}} s, 3^{\underline{a}} s, 4^{\underline{a}} s$ e $5^{\underline{a}} s$ séries, respectivamente;

d) a repetição de série uma, duas, três, quatro e até 5 vezes é fato que tem ocorrido nas escolas do estado, obrigando muitas vezes o aluno a permanecer na escola primária, sete, oito, nove e até dez anos, sem que muitas vezes, tenha concluído o curso;

e) enfim, soma de conhecimentos e técnicas dominadas por $70 \%$ dos escolares primários de Pernambuco é deficiente e não satisfaz aos propósitos de uma escola fundamental.

NOTAS:

$1^{\text {a }}$ - Vejam-se os quadros demonstrativos que acompanham o relatório da $2^{\underline{a}}$ Comissão;

$2^{\text {a }}$ - Faltam dados sobre a instabilidade da população sertaneja, ou seja, sobre 


\section{Trabalhonecessário}

Issn: 1808 - 799X

ano $11, \mathrm{n}-16-2013$

o seu deslocamento, sobretudo em períodos de estiagem prolongada, o que, como é óbvio, deverá pesar, e muito, no baixo índice de alfabetização do estado.

\section{SUGESTÕES PARA UMA SOLUÇÃO:}

a) Levar o governo federal a suprir as deficiências da rede escolar nos estados deficitários, de modo a que possa cumprir a Lei de obrigatoriedade do ensino primário, realizando-se simultaneamente campanhas reeducativas, neste sentido;

b) Oferecer facilidades à iniciativa particular, em tudo que diga respeito à difusão da cultura, sem diminuição das responsabilidades do Estado, neste setor de atribuições;

c) Manter a escola gratuita, mediante a execução de um vasto plano educacional, que atinja a todos os recantos do país, aberta a todos os seus habitantes, com efetiva igualdade de oportunidades, porque "educação não é privilégio";

d) Aplicar, em cada unidade da Federação, os fundos de educação Estadual, previstos pela Constituição, em sua exata proporcionalidade;

e) Efetivar um inteligente plano de descentralização do ensino, dando aos estados maiores oportunidades de aplicação dos seus sistemas escolares, bem como de aplicação das verbas federais que Ihes forem destinadas;

f) Rever cuidadosamente a rede escolar em função, mediante informação de Inspetorias locais, tendo em vista a supressão e localização de cadeiras nas zonas mais adequadas;

g) Assistir tecnicamente o professorado por meio de estágios, cursos, reuniões, círculos de estudo, mesas redondas, seminários, e pelo fortalecimento e 


\section{Trabalhonecessário}

Issn: $1808-799 X$

ano $11, \mathrm{n}-16-2013$

empréstimos de monografias, livros didáticos especializados, instruções, planos de trabalho, etc;

h) Selecionar os elementos mais capazes do magistério de modo que possam cumprir com acerto a dedicação às funções a que se destinam;

i) Organizar o currículo da escola primária de forma que o processo educativo se

exerça sem paradas, lacunas ou evasões, atendendo a programas flexíveis e adaptados às possibilidades do educando e às necessidades locais;

j) Conceituar exatamente os termos - alfabetizar, alfabetização - libertando a escola de conceitos tradicionais que levam ao impedimento de promoção de grau aos 33\% de alunos matriculados nas escolas primárias e à evasão de $90 \%$ de seus alunos até a conclusão de Curso.

k) Combater sem tréguas o pauperismo e a ignorância das populações nordestinas, mediante um vasto plano civilizado, de aplicação imediata, aproveitando os recursos da eletrificação, irrigação, drenagem e açudagem, com o aproveitamento integral da energia de Paulo Afonso, obtendo-se uma industrialização bem planejada e a racionalização dos métodos de aproveitamento do solo.

$3^{\mathrm{a}}$ Comissão

Tema: A EDUCAÇÃO DOS ADULTOS E AS POPULAÇÕES DE MARGINAIS: O PROBLEMA DOS MOCAMBOS.

a) Apesar de serem considerados "marginais" todos aqueles que não se integram perfeitamente na vida social, dependendo como tal serem incluídos os inválidos de todos os tipos, os mendigos, as prostitutas, os fora da lei, em geral, a Comissão se fixou naqueles que residem em mocambos, este foi 0

TrabalhoNecessário - www.uff.br/trabalhonecessario; Ano 11, № 16/2013. 


\section{Trabalhonecessário}

Issn: 1808 - 799X

ano $11, \mathrm{n}-16-2013$

tema que lhe coube, bem ajustado a uma das formas de habitação típica de grande parte dos marginais de Recife;

b) É de todo louvável o esforço do conhecimento das peculiaridades regionais brasileiras, de nosso contorno social e histórico;

c) O que mais enfaticamente nos interessa, no momento que passa, é na nossa "sobrevivência histórica do povo que vem vivendo a sua promoção de ser colonial, em ser nacional"; do "ser objeto de pensamento de outros, em ser sujeito do seu próprio pensamento" (Vieira Pinto). E ao mesmo tempo, o estabelecimento de bases para nosso regime de vida e de trabalho, que de simplesmente agrícola, latifundiário, paternal e escravocrata, se transforma no de um país que se industrializa, inserida em um processo de desenvolvimento e de mudanças rápidas;

d) É tempo de, atendendo a estes imperativos, considerar a indispensabilidade da consciência de processo de desenvolvimento, por parte do povo, a emersão desse povo na vida pública nacional como interferente em todo o trabalho de elaboração, participação e decisão responsáveis em todos os momentos da vida pública - como convém à estrutura o funcionamento de uma democracia;

e) Tomando em consideração muito especial o problema dos mocambos, vemos que estes, situados nos córregos e morros, mangues e areais do Recife, abrigam habitantes nem sempre marginais, mais de três tipos sociais distintos:

1. o proletariado assalariado; 2. o subproletariado, vivendo de "biscates"; 3. o mendigo, real ou falso.

O primeiro, fazendo parte sistemática do circuito econômico; o segundo fora do circuito em caráter permanente e esforçando-se para nele penetrar; o terceiro, improdutivo e refletindo mais fortemente esse aspecto da nossa patologia social.

TrabalhoNecessário - www.uff.br/trabalhonecessario; Ano 11, № 16/2013. 


\section{Trabalhonecessário}

Issn: 1808 - 799X

ano $11, \mathrm{n}-16-2013$

Essas zonas se situam na parte urbana, suburbana ou rurbana de Recife, e vem recebendo o impacto constante de populações rurais do estado e de outros estados da região, dando como resultado o que o sociólogo Gilberto Freyre já chamou de "inchação do Recife".

\section{SUGESTÕES PARA UMA SOLUÇÃO:}

Conhecida tão criticamente quanto possível essa realidade, em mudança constante, passará o processo educativo a trabalhá-la, de um modo aliás que parece convir a todo o território nacional, sobretudo onde houver maior concentração de desajustes sociais:

a) Rever em todos os seus aspectos, a inadaptação dos transplantes que agiram sobre o nosso sistema educativo, com aproveitamento dos positivos que passam ser adaptados á nova realidade;

b) Proporcionar ao homem um preparo técnico especializado, para poder interferir, de fato, no "processo de desenvolvimento" do país. Equivale a dizer: fazê-lo sair da condição de marginal para a de participante do trabalho, da produção, do rendimento. Aí vale a pena ressaltar ainda o papel das escolas profissionais e rurais, de todos os tipos;

c) Impedir que o trabalho educativo se faça sobre ou para o homem, do tipo apenas alfabetizador ou de penetração auditiva simplesmente, substituindo-o por aquele outro que se obtém com o homem; evidentemente mais uma vez imperativo de sua participação em todos os momentos do trabalho educativo, preparatória ou concomitante àquela outra ainda mais estimável, que é participação na vida da região e nas esferas mais amplas da sociedade em que vive;

d) Organizar cursos de todos os tipos, para as zonas mais populosas, onde 


\section{Trabalhonecessário}

Issn: 1808 - 799X

ano $11, \mathrm{n}-16-2013$

maior concentração houver de desajustados, de duração rápida, intensiva, ou prolongados, cujos programas devem ser, em parte, planejados com os alunos, para que correspondam à sua realidade existencial. Convém ainda lembrar os que se processam sob regime de internato, quando os recursos o permitirem. Nestes cursos seria dada ênfase ao ensino técnico e agrícola de acordo com a especial destinação de cada um deles. Ao lado destes, os de arte culinária, arranjos do lar, higiene e puericultura, corte e costura, pequenas indústrias caseiras, com vistas ao aumento do poder aquisitivo da família;

e) Criar, posteriormente aos grupos de estudos, os grupos de ação dentro do espírito do auto-governo, agindo sobre problemas mais simples da vida local: buracos das ruas, poças de lama, combate às muriçocas e aos animais daninhos, construção de fossas, realização de feiras, programas esportivos e recreativos em geral, etc. Até uma interferência ativa na vida religiosa, econômica, política, do distrito, do município, do estado e do país;

f) Articular o trabalho das escolas de adultos com as instituições existentes, para crianças, onde funcionam "Clubes de Pais", de modo a fortalecer por mais este meio, os laços de união entre família e a escola;

g) Interessar as instituições beneficentes e particulares de todos os tipos que se interessem por este trabalho de recuperação de adultos, bem como as de pesquisa social e pedagógica - estas fornecendo ao educador os elementos para uma ação positiva e realista;

h) Criar uma mentalidade nova no educador, a par de um preparo especializado que está a exigir esta forma especial de participação sua no trabalho de erguimento do país;

i) Renovar os métodos e processos educativos, sem a rejeição dos exclusivamente auditivos. Substituir o discurso pela discussão. Utilizar modernas técnicas de educação de grupos, com recursos áudios-visuais, 


\section{Trabalhonecessário}

Issn: $1808-799 X$

ano 11, no $16-2013$

ativos e funcionais, aproveitando o cinema, a dramatização, o rádio, a imprensa, etc.

TrabalhoNecessário - www.uff.br/trabalhonecessario; Ano 11, № 16/2013. 


\section{Trabalhonecessário}

Issn: 1808 - 799X

ano $11, \mathrm{n}-16-2013$

\section{Documento 2:}

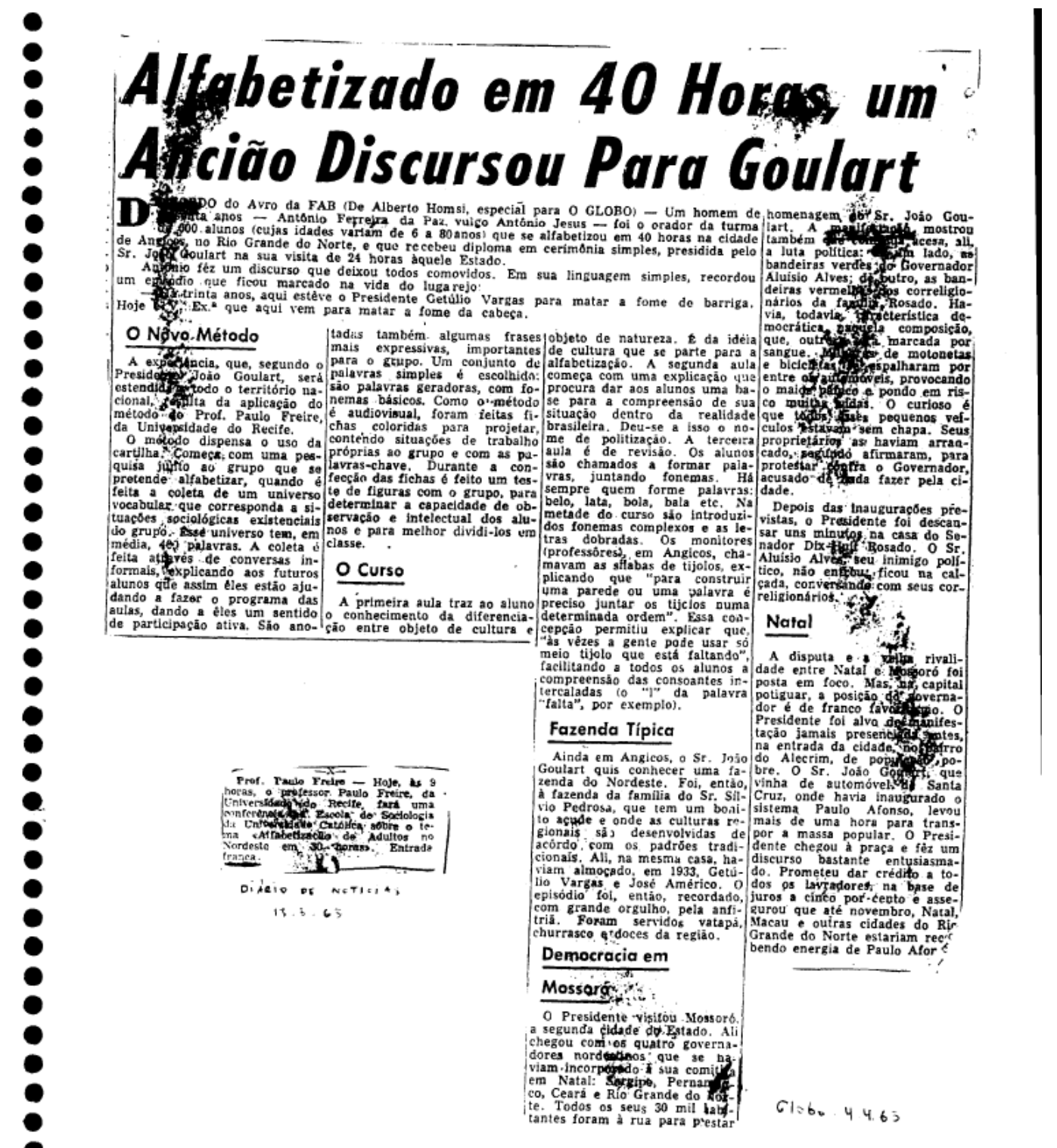

INSTITUTO PAULO FREIRE Rua Cerro Corá, $55020^{\circ}$ andar cj. 22 Te!: (II) 3021-5536 Fax: (11) 3021-5589 05061-100 - São Paulo - SP - Brasil E-mail: ipf@paulofreire.org

Fonte: http://acervo.paulofreire.org/xmlui/handle/7891/3135\#page/1/mode/1up

TrabalhoNecessário - www.uff.br/trabalhonecessario; Ano 11, № 16/2013. 


\title{
Trabalhonecessário
}

\author{
Issn: 1808 - 799X \\ ano 11 , no $16-2013$
}

\section{Documento 3}

Texto de Antonio Callado http://forumeja.org.br/files/materia.inteira.jpg (Jornal do Brasil, 15 de janeiro de 1964)

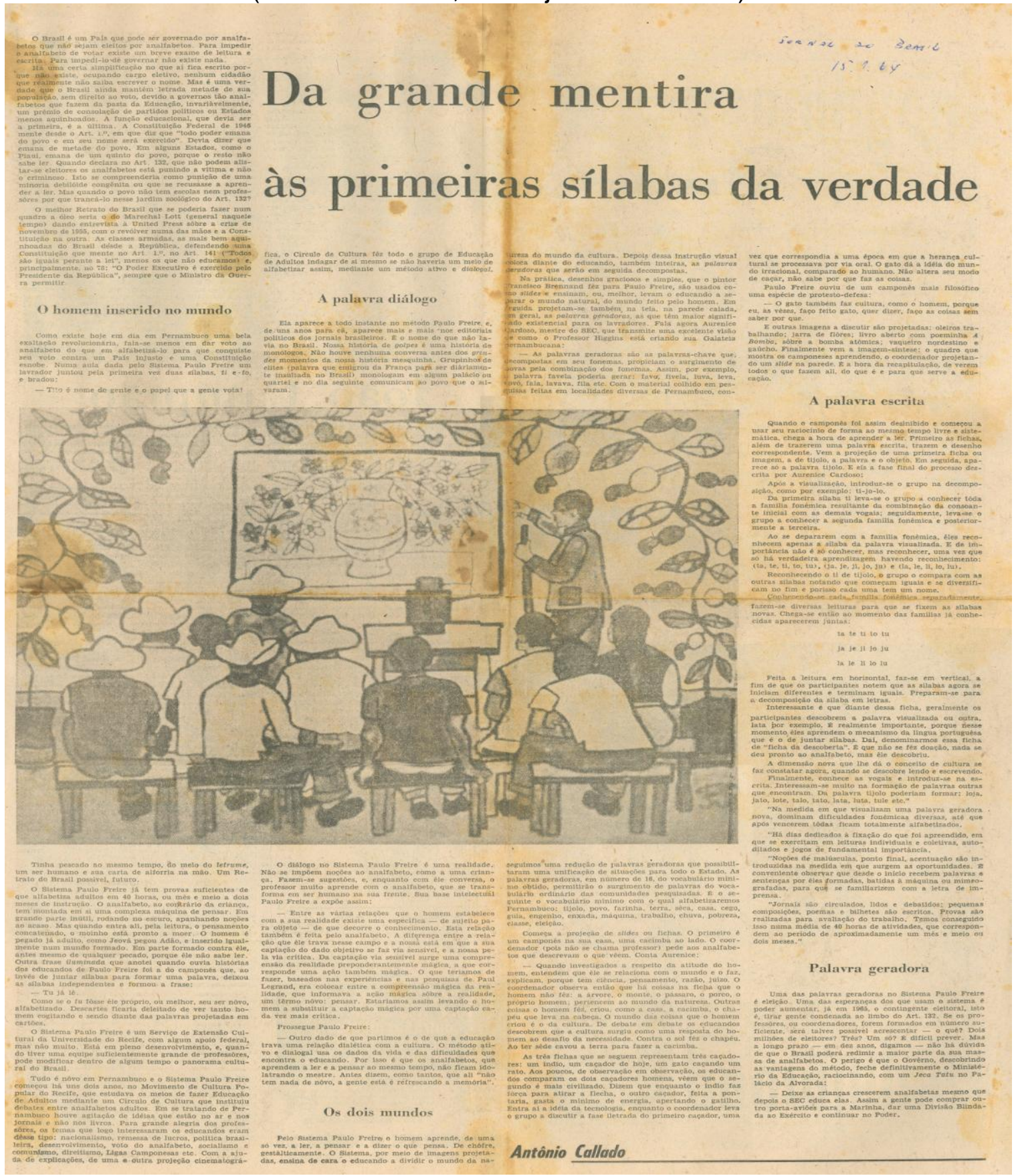

TrabalhoNecessário - www.uff.br/trabalhonecessario; Ano 11, № 16/2013. 


\title{
Trabalhonecessário
}

Issn: 1808 - 799X

ano $11, \mathrm{n}-16-2013$

\section{Documento 4:}

Decreto no 53.465 , de 21 de Janeiro de 1964

\author{
Institui o Programa Nacional de Alfabetização do \\ Ministério da Educação e Cultura e dá outras \\ providências.
}

O PRESIDENTE DE REPÚBLICA, no uso das atribuições constante do artigo 87, inciso I, da Constituição Federal, e, CONSIDERANDO a necessidade de um esfôrço nacional concentrado para eliminação do analfabetismo;

CONSIDERANDO que os esforços até agora realizados não têm correspondido à necessidade de alfabetização em massa da população nacional;

CONSIDERANDO que urge conclamar e unir tôdas as classes do povo brasileiro no sentido de levar o alfabeto àquelas camadas mais desfavorecidas que ainda o desconhecem;

CONSIDERANDO que o Ministério da Educação e Cultura vem provando, através da Comissão de Cultura Popular, com vantagem o Sistema Paulo Freire para alfabetização em tempo rápido;

DECRETA:

Art. 1ํ Fica instituído o Programa Nacional de Alfabetização, mediante o uso do Sistema Paulo Freire, através do Ministério da Educação e Cultura.

Art. 2ำ Para execução do Programa Nacional de Alfabetização, nos têrmos do artigo anterior, o Ministro da Educação e Cultura constituirá uma Comissão Especial e tomará todas as providências necessárias.

Art. 3ㅇ O Ministério da Educação e Cultura escolherá duas áreas no Território Nacional para início da operação do Programa de que trata o presente Decreto. Art. 4ำ A Comissão do Programa Nacional de Alfabetização convocará e utilizará a cooperação e os serviços de: agremiações estudantis e profissionais, associações esportivas, sociedades de bairro e municipalistas, entidades religiosas, organizações governamentais, civis e militares, associações

TrabalhoNecessário - www.uff.br/trabalhonecessario; Ano 11, № 16/2013. 


\section{Trabalhonecessário}

Issn: 1808 - 799X

ano $11, \mathrm{n}-16-2013$

patronais, emprêsas privadas, órgãos de difusão, o magistério e todos os setores mobilizáveis.

Art. 5 São considerados relevantes os serviços prestados à campanha de alfabetização em massa realizada pelo Programa Nacional de Alfabetização. Art. 6 A execução e desenvolvimento do Programa Nacional de Alfabetização ficarão a cargo da Comissão Especial de que trata o Artigo 2‥

Parágrafo único. O Ministro da Educação e Cultura expedirá, em tempo oportuno, portarias contendo o regulamento e instruções para funcionamento da Comissão, bem como para desenvolvimento do Programa.

Art. $7^{\circ}$ Revogam-se as disposições em contrário.

Brasília, 21 de janeiro de 1964; 143ํ da Independência e 76ํ da República. JOÃO GOULART Júlio Furquim Sambaquy 


\title{
Trabalhonecessário
}

Issn: 1808 - 799X

ano $11, \mathrm{n}-16-2013$

\section{Documento 5:}

Decreto ํㅜ 53.886, de 14 de Abril de 1964

\author{
Revoga o Decreto n. 53.465, de 21 de janeiro de \\ 1964, que instituiu o Programa Nacional de \\ Alfabetização do Ministério da Educação e \\ Cultura.
}

O PRESIDENTE DA CÂMARA DOS DEPUTADOS, no exercício do cargo de PRESIDENTE DA REPÚBLICA, no uso das atribuições constantes do art. 87, inciso I, da Constituição Federal e CONSIDERANDO a necessidade de reestruturar o Planejamento para a eliminação do analfabetismo no país;

CONSIDERANDO ainda que o material a ser empregado na Alfabetização da População Nacional deverá veicular idéias nitidamente democráticas e preservar as instituições e tradições de nosso povo;

CONSIDERANDO, finalmente, que o Departamento Nacional de Educação é o órgão do Ministério da Educação e Cultura ao qual incumbe, por lei, a administração dos assuntos de educação,

DECRETA:

Art. $1^{\circ}$ Fica revogado o Decreto $n^{0} 53.465$, de 21 de janeiro de 1964, que instituiu o Programa Nacional de Alfabetização do Ministério da Educação e Cultura.

Art. 2ㅇ Departamento Nacional de Educação recolherá todo o acervo empregado na execução do Programa Nacional de Alfabetização, cujos recursos também ficarão à disposição daquele órgão.

Art. $3^{\circ} \mathrm{O}$ Ministro da Educação e Cultura baixará os atos que se tornarem necessários para a execução dêste Decreto.

Art. 4ํำ presente Decreto entrará em vigor na data de sua publicação.

TrabalhoNecessário - www.uff.br/trabalhonecessario; Ano 11, № 16/2013. 
Issn: $1808-799 X$

ano 11, no $16-2013$

Brasília, 14 de abril de 1964; 143ํ da Independência e 76ํ da República.

RANIERI MAZZILLI Luiz Antônio da Gama e Silva

\section{Documentos 6 e 7:}

Entrevistas gravadas e disponíveis sobre Angicos:

a) Osmar Fávero - https://www.youtube.com/watch?v=z9xjLADzLIA

b) Marcos Guerra - https://www.youtube.com/watch?v=Y xt6ZxW7EM

TrabalhoNecessário - www.uff.br/trabalhonecessario; Ano 11, № 16/2013. 


\section{Trabalhonecessário}

Issn: 1808 - 799X

ano $11, \mathrm{n}-16-2013$

\section{Referências bibliográficas}

FERNANDES, Calazans e TERRA, Antonia. 40 horas de esperança. O método Paulo Freire: política e pedagogia na experiência de Angicos. São Paulo; Ática, 1994.

FREIRE, Paulo. A educação como prática de liberdade. Rio de Janeiro: Paz e Terra, 1967.

- Pedagogia do Oprimido. Rio de Janeiro: Paz e Terra, 1974. . Cartas a Cristina. Rio de Janeiro: Paz e Terra, 1994.

LYRA, Carlos. As quarenta horas de Angicos: uma experiência pioneira em educação. São Paulo: Cortez, 1996. 


\section{Trabalhonecessário}

Issn: 1808 - 799X

ano 11, no $16-2013$

Fotos:

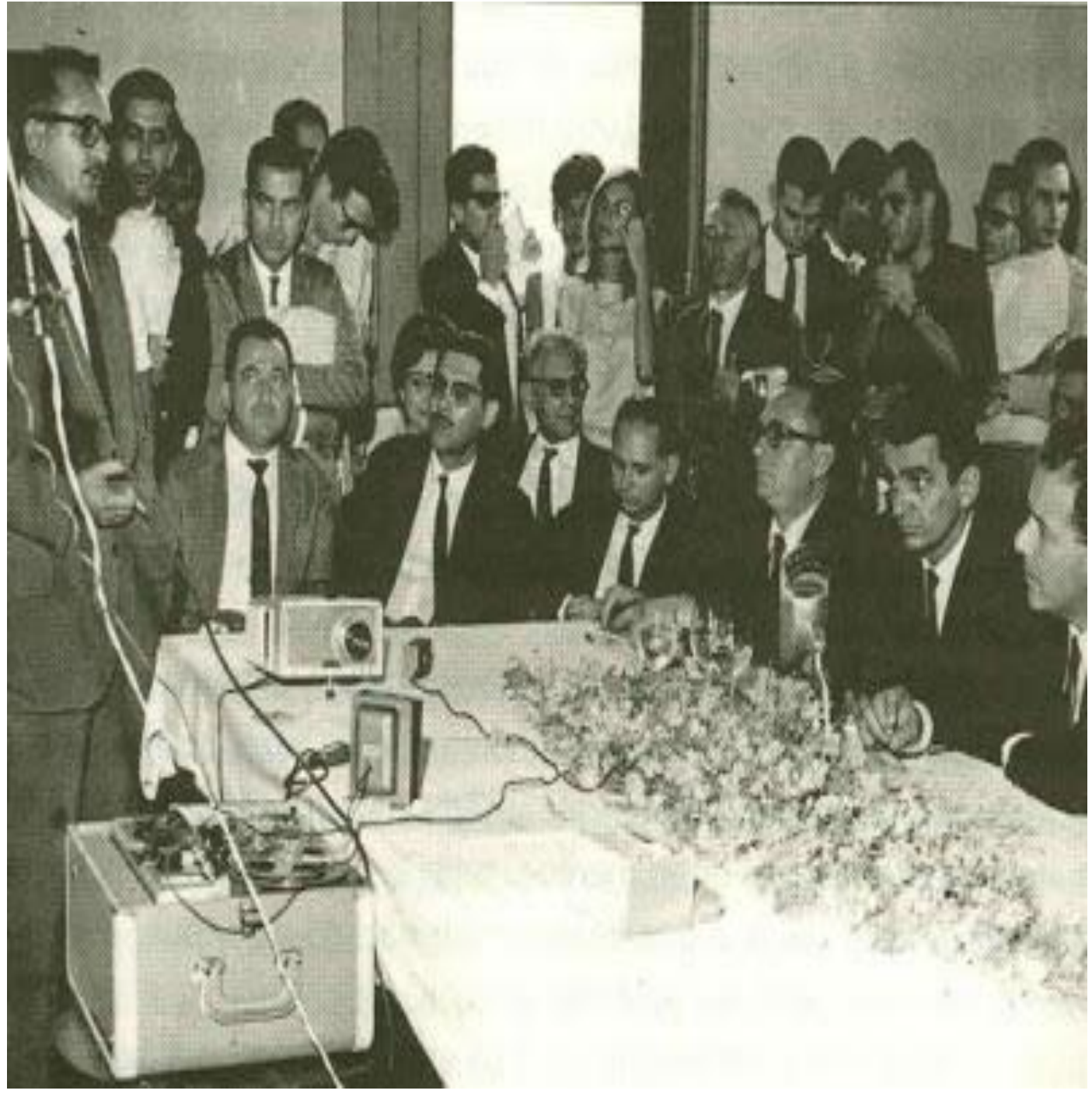

Paulo Freire expõe a metodologia ao Presidente João Goulart e Governadores

TrabalhoNecessário - www.uff.br/trabalhonecessario; Ano 11, № 16/2013. 


\section{Trabalhonecessário}

Issn: 1808 - 799X

ano 11, no $16-2013$

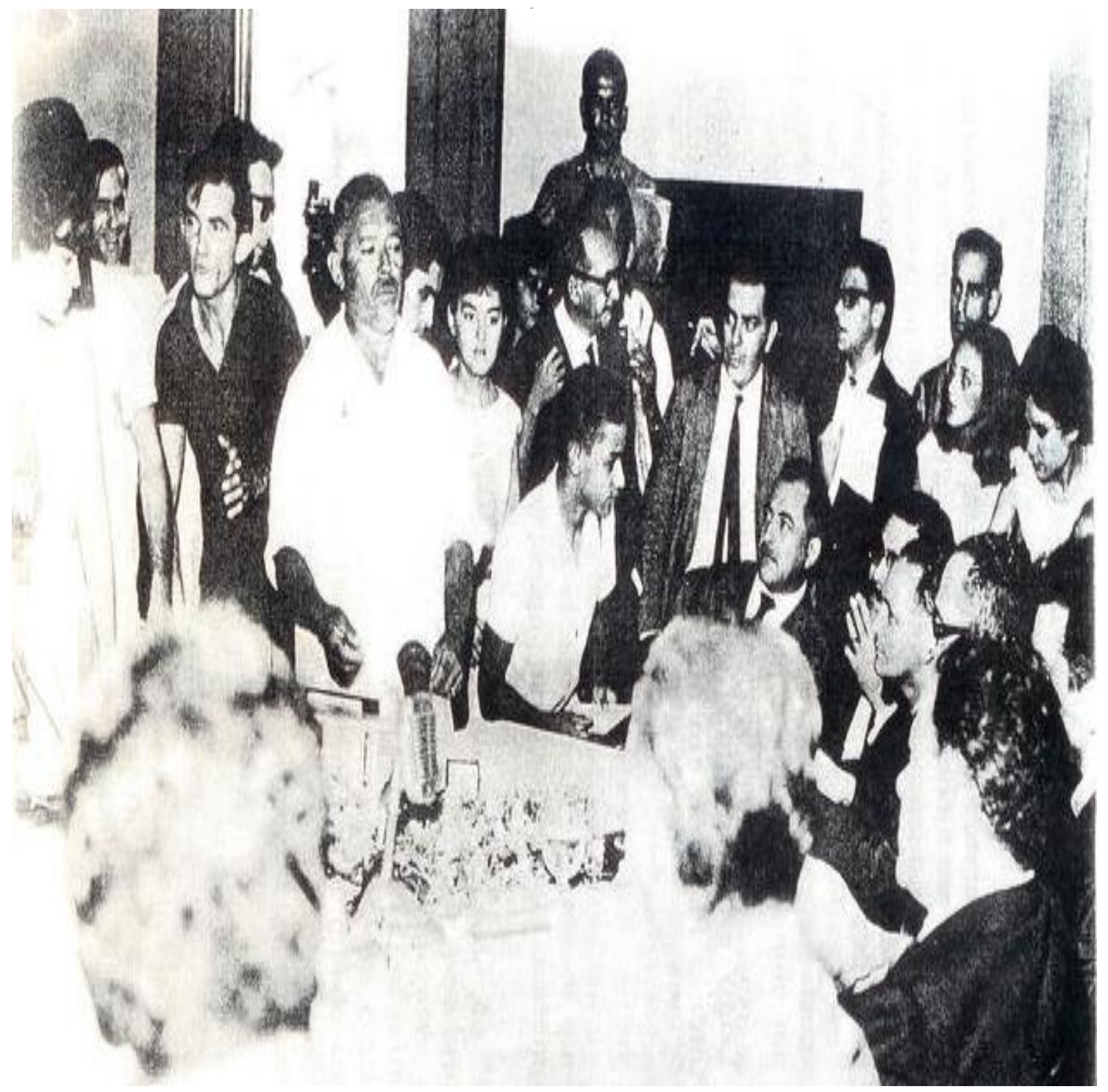

Antonio Ferreira discursa no encerramento diante do Presidente João Goulart 